Metastases of renal clear cell carcinoma to the organs of the head are rare. Single cases show that they can appear either shortly after or many years after radical surgery. The diagnosis of this cancer is difficult because of its insidious course; therefore, it is often diagnosed too late. Late diagnosis is associated with a high risk of distant metastases and increased mortality. The paper presents a case of a patient whose kidney tumour was diagnosed during hospitalisation at the Department of Rheumatology. Further diagnosis and surgical treatment were performed in the Department of Urology, where a left-sided nephrectomy was carried out. After two years, the patient was hospitalised in the Department of Otolaryngology due to dysphagia. The patient was subjected to fine-needle biopsy, surgical biopsy, CT, and ultrasound. Metastases of renal clear cell carcinoma were diagnosed based on a histopathological examination and the results of imaging studies. Due to the extent of the tumour, diagnostics were extended to magnetic resonance imaging. The patient was qualified for tracheotomy, cytoreductive surgery, and chemoradiation. The patient was referred for further treatment at the Centre of Oncology in Bydgoszcz.

Key words: metastases, renal clear cell carcinoma.

Contemp Oncol (Pozn) 2014; 18 (6): 448-45 DOI: $10.5114 /$ wo. 2014.47474

\section{Multiple metastases of renal clear cell carcinoma to the organs of the head}

\author{
Piotr Sawicki, Wojciech Kaźmierczak, Paweł Burduk, Henryk Kaźmierczak
}

Department of Otolaryngology, Ludwik Rydygier Medical College in Bydgoszcz, Nicolaus Copernicus University in Toruń, Poland

The incidence of metastasis from distant foci to the ENT organs is rare, but the percentage has increased in recent years along with the growth of the overall incidence of cancer [1-4]. Clear cell renal carcinoma typically metastasises to the lungs, bones, brain, ovary, and prostate. The spread to other organs is casuistic $[5,6]$. It constitutes approximately $90 \%$ of malignant neoplasm of the kidney, and there is a high incidence of metastases to other organs [7, 8]. In a few documented cases, distant metastases appeared many years after treatment of the primary tumour [9, 10].

Because of its insidious course, clear cell renal carcinoma is often not recognised for a long time. This predisposes to the formation of distant metastases, which are often the first sign of cancer. Distant metastases spread both through the blood and the lymph vessels. The histological structure reveals cells with clear cytoplasm. It contains large amounts of phospholipids and triglycerides. These components are removed from the cells during the treatment of a preparation, which is observed microscopically as an "empty cell" [11].

In the presented case, a renal tumour was detected during diagnostic tests for systemic disease. Metastatic changes were not reported at that time.

\section{Case report}

A 63-year-old patient, J.M., was admitted to the Department of Otolaryngology and ENT Oncology at the Medical College in Bydgoszcz of the Nicolaus Copernicus University in October 2012 due to a tumour of the tongue base, located on the right side together with ulceration of the alveolar part of the mandible on the same side.

In 2009, the patient was diagnosed with a kidney tumour while being hospitalised at the Department of Rheumatology of the 10th Military Clinical Hospital in Bydgoszcz. The patient was then transferred to the Department of Urology, where he underwent left-sided nephrectomy. The histopathological examination revealed clear cell carcinoma of the left kidney (G-2, pT2, NO). A tumour $6 \times 4 \mathrm{~cm}$ in diameter was located slightly above the surface of the kidney; it did not infiltrate the hilus (at a distance of 3-4 cm) or the tumour capsule. The perirenal adipose tissue and the adrenal gland were free from tumour infiltration.

In September 2012, the patient was hospitalised because of dysphagia at the Department of Otolaryngology. During hospitalisation, a biopsy of the tumour located on the tongue base, on the right side, showed no infiltration of the lower jaw. The histological examination demonstrated malignant cancer cells and hypocellular bloody aspirates; the uncertain cytological image may correspond to the metastatic lesion of clear cell renal carcinoma.

Computed tomography revealed a pathological, irregular lesion located at the bottom of the oral cavity, on the right side and medially, ranging from the root of the tongue to the level of the hyoid bone, which was reinforced after contrast administration (size $44 \times 64 \times 76 \mathrm{~mm}$ ). It reached the lower 
jaw in the front part and the hyoid bone in the lower part, without any signs of bone destruction. It connected with the epiglottis in the lower part. It crossed the midline. The submandibular lymph nodes measured $7-8 \mathrm{~mm}$. In the medial part of the left cerebellar hemisphere, just below the fourth ventricle, there was an area of strong enforcement measuring $9 \times 13 \times 10 \mathrm{~mm}$, a focal lesion, which demanded further diagnosis (Figs. 1-4).

In October 2012, the patient was admitted for further evaluation to the Department of Otolaryngology and ENT Oncology with the Unit of Audiology and Phoniatrics of the Medical College in Bydgoszcz, Nicolaus Copernicus Universi-

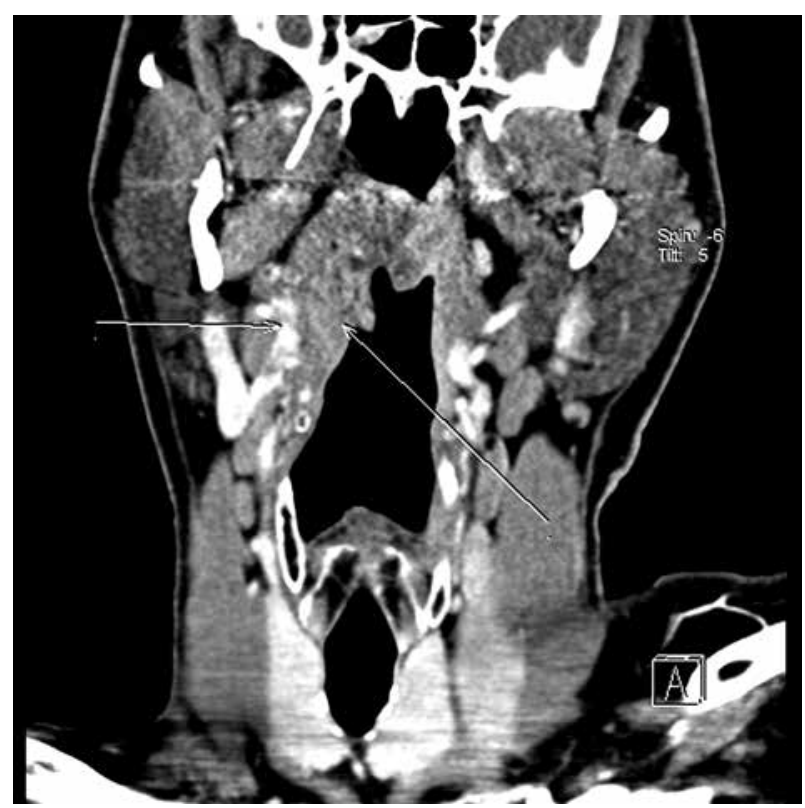

Fig. 1. Computed tomography performed on 21.09.2012 - frontal projection

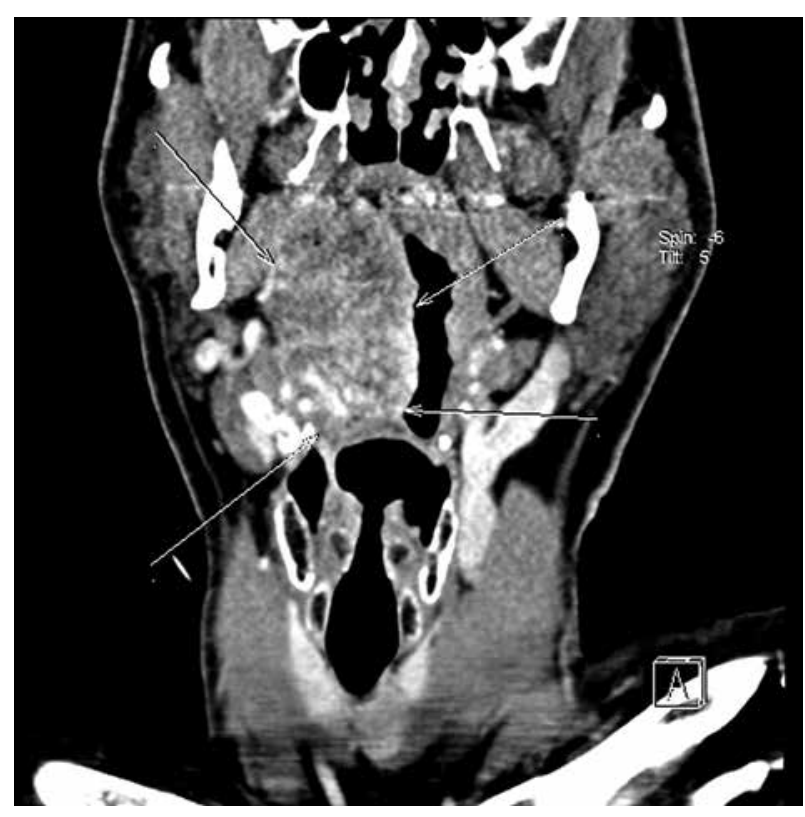

Fig. 3. Computed tomography performed on 21.09.2012 - frontal projection ty. Medical history revealed pain of the right half of the head and difficulty in swallowing. Physical examination showed ulceration in the toothless part of the alveolar mandible, on the right side, measuring $1.5 \times 3 \mathrm{~cm}$, limited mobility of the tongue, and palpation noticed induration within the base of the tongue, on the right side, covered with a smooth mucous membrane. Examination of the lymphatic system found enlarged and mobile lymph nodes, on both sides, not exceeding $1 \mathrm{~cm}$. Due to the uncertain nature of the lesion revealed in test number 26465 , the patient was qualified for biopsy of the specimen taken from the tumour of the tongue base under local anaesthesia.

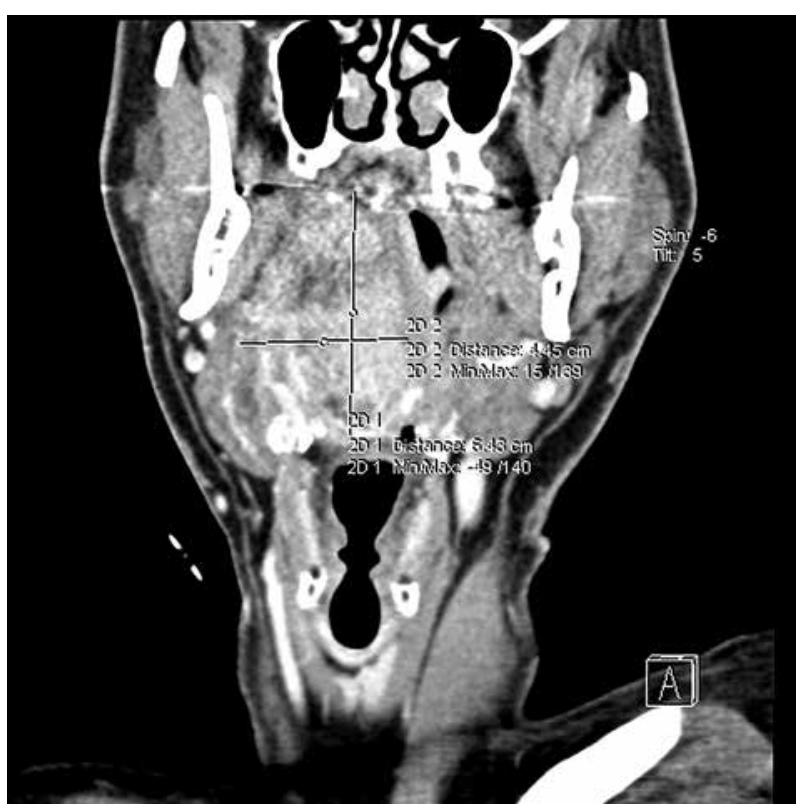

Fig. 2. Computed tomography performed on 21.09.2012 - frontal projection

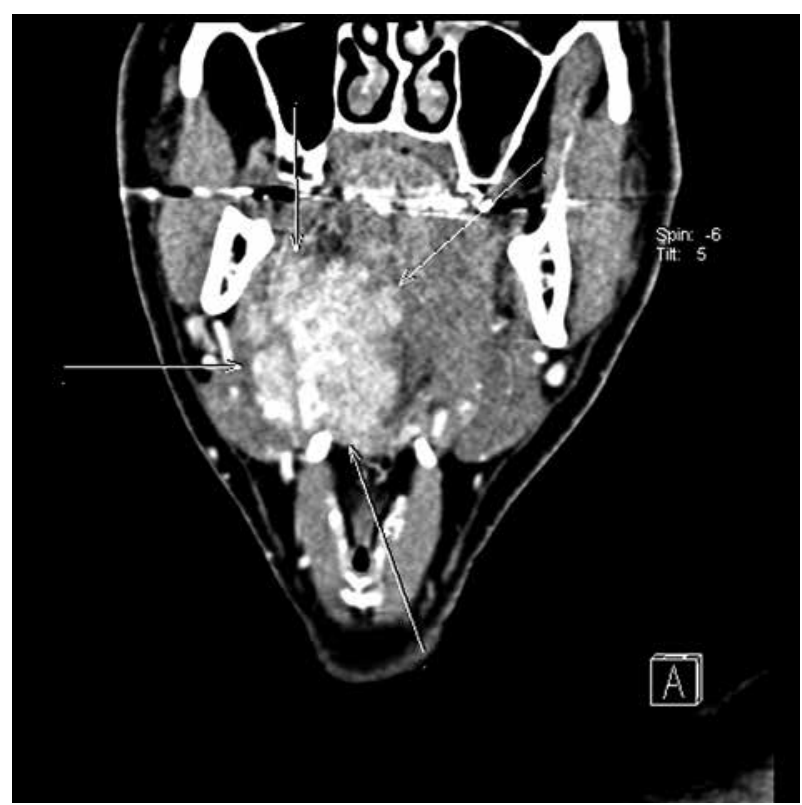

Fig. 4. Computed tomography performed on 21.09.2012 - frontal projection 


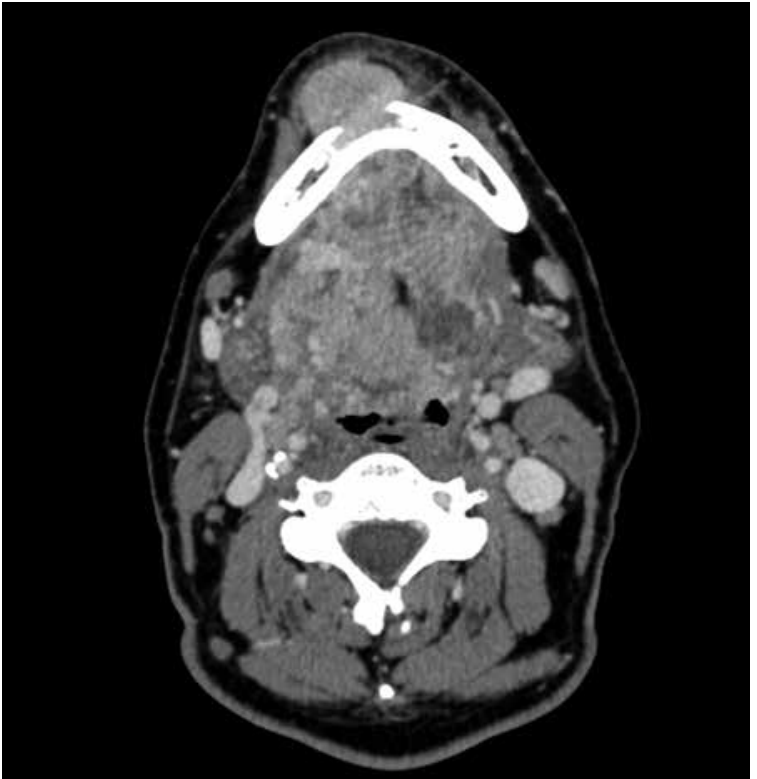

Fig. 5. Computed tomography performed on 03.12.2012 - transverse projection

The result of test No. 6196 was cancerous metastases. The test examined tissue material with a total diameter of $1.5 \mathrm{~cm}$ and creamy-brown colour. The results of immunohistochemical tests for the basic lesion were as follows: CD10 (+), Vimentin (+), Ki 67 index about 30\%, SMA-positive reaction in the vascular walls, and CK HMW (negative). Microscopic and immunohistochemical tests supported the primary renal location of the tumour. In addition, a specimen was collected for histopathological examination from ulceration within the body of the mandible. The result of test No. 6631 was metastasis of clear cell carcinoma.

Computed tomography (CT) performed during hospitalisation showed an area of strong contrast enhancement covering the base of the tongue, the muscles of the oral bottom, the mental area (destruction of the bone of the

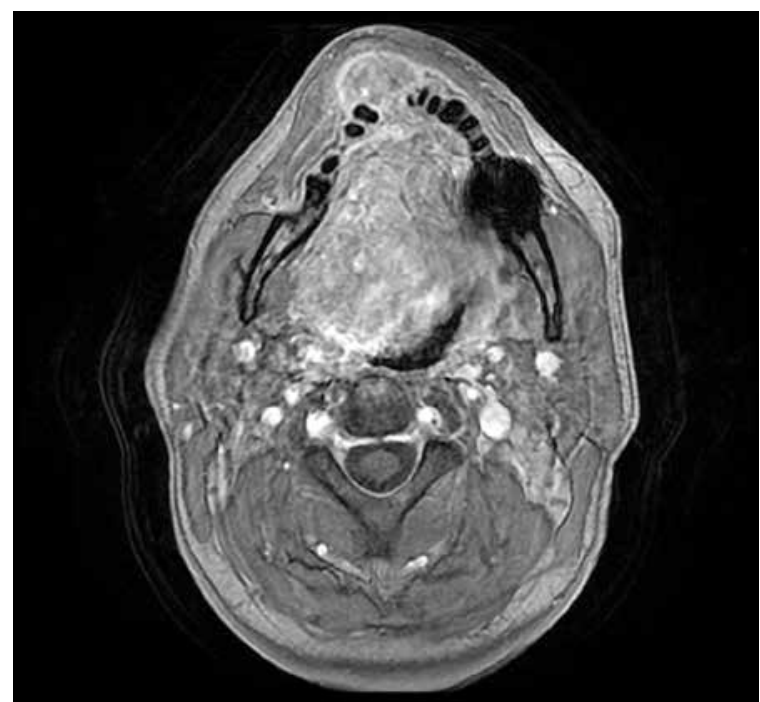

Fig. 7. Magnetic resonance imaging performed on 03.12.2012 transverse projection

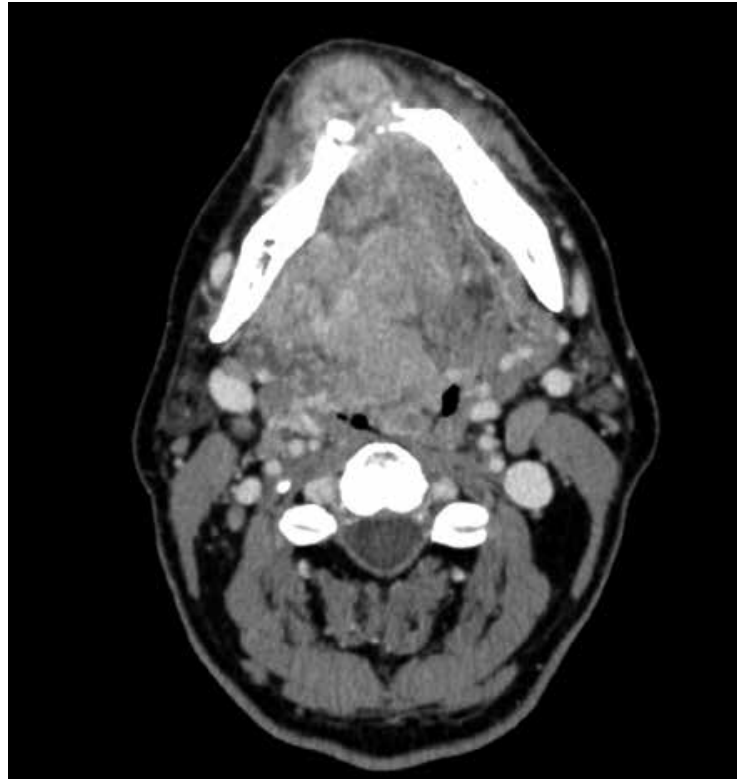

Fig. 6. Computed tomography performed on 03.12.2012 -transverse projection

lower jaw at this level, $3.5 \mathrm{~cm}$ long), pre-epiglottic space to the hyoid bone, the right side of the pharyngeal wall, right submandibular salivary gland, and the area of the right vascular nerve bundle. In addition, it was found that at the border of the left hemisphere of the cerebellum and vermis, there was a focus of the contrast enhancement measuring $15 \times 8 \times 12 \mathrm{~mm}$ - probably a metastatic lesion [further magnetic resonance imaging (MRI) evaluation was recommended]. At the top of the left lung, there was a nodule of size $8 \mathrm{~mm}$ [further positron emission tomography/computed tomography (PET/CT) evaluation is recommended] (Figs. 5, 6).

The MRI findings revealed a pathological mass covering the tongue and its base; on the right side, it exceeded the midline, had a rough outline, and infiltrated the muscular

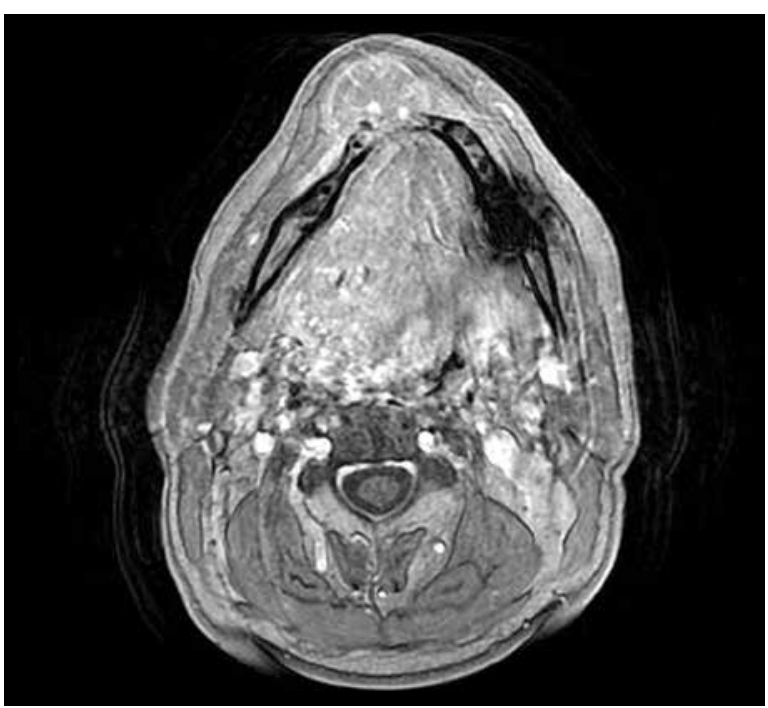

Fig. 8. Magnetic resonance imaging performed on 03.12.2012 transverse projection 
floor of the mouth. Anteriorly, the mass invaded the lower jaw. Part of it, measuring $26 \times 27 \times 31 \mathrm{~mm}$, pressed into the interdental space and led to the front of the lower jaw. Posteriorly, the mass covered the entire lumen of the throat adhering to the rear wall, taking up the pre-epiglottic space and infiltrating the right parotid and submandibular gland. In addition, on the border of the left hemisphere of the cerebellum and the vermis, there was a sharply restricted isointense focus enhanced by the contrast, of size $14 \times 11 \times 14 \mathrm{~mm}$, which was probably metastatic (Figs. 7, 8).

Due to the extensive local progression of metastases within the throat and the mouth, as well as metastatic changes reported in the clinical imaging, the patient was qualified for tracheotomy and cytoreductive surgery of the mandible. Partial resection of the mandibular body was performed, including the tumour. Postoperative complications were not observed. After neurological and psychological consultation, the patient was referred to the Centre of Oncology in Bydgoszcz for further radio-chemotherapeutic treatment.

\section{Discussion}

Kidney cancer constitutes between 2 and $3.75 \%$ of malignancies in men. In 2.7 to $2.91 \%$ of cases it leads to death, and five-year survival is more than $35 \%$ of treated patients [12]. Due to the rarity of clear cell renal carcinoma metastases to the head and neck, the literature describes relatively few cases of such location [13-15]. The primary lesion is often asymptomatic for several months. This increases the risk of developing metastases, which may occur even 10 years after operation of the kidney tumour. Despite a good understanding of clear cell carcinoma histology, the image of metastatic lesions may present many diagnostic difficulties due to various shapes of its cells and anisochromia [16]. In our patient, the tumour of the tongue, which caused pain and dysphagia, occurred two years after urological surgery and quickly infiltrated the floor of the mouth. Taking into account the results of imaging studies, it is difficult to specify whether the pathology within the body of the mandible is simply another metastatic focus or infiltration spreading from the soft tissues of the mouth floor. Resection of part of the mandibular body was carried out to improve the quality of life in the patient at this stage of the disease. The focus within the hemisphere and the cerebellar vermis did not produce neurological symptoms, but they were detected during the search for other distant metastases. Because of the extent of metastases in the oral part of the throat, the patient was secured by tracheostomy. Due to the number of distant metastases typical of clear cell renal carcinoma, the patient was referred for radio-chemotherapeutic treatment to improve his quality of life $[17,18]$.

\section{References}

1. Maestre-Rodríguez O, González-García R, Mateo-Arias J, MorenoGarcía C, Serrano-Gil H, Villanueva-Alcojol L, Campos-de-Orellana AM, Monje-Gil F. Metastasis of renal clear-cell carcinoma to the oral mucosa, an atypical location. Med Oral Patol Oral Cir Bucal 2009; 14: e601-4.
2. Narea-Matamala G, Fernández-Toro Mde L, Villalabeitía-Ugarte E, Landaeta-Mendoza M, Rojas-Alcayaga G. Oral metastasis of renal cell carcinoma, presentation of a case. Med Oral Patol Oral Cir Bucal 2008; 13.

3. Pritchyk KM, Schiff BA, Newkirk KA, Krowiak E, Deeb ZE. Metastatic renal cell carcinoma to the head and neck. Laryngoscope 2002; 112: 1598-602.

4. McLaughlin JK, Lipworth L, Tarone RE. Epidemiologic aspects of renal cell carcinoma. Semin Oncol 2006; 33: 527-33.

5. Jin R, Craddock KJ, Irish JC, Perez-Ordonez B, Weinreb I. Recurrent hyalinizing clear cell carcinoma of the base of tongue with high-grade transformation and EWSR1 gene rearrangement by FISH. Head Neck Pathol 2012; 6: 389-94.

6. Haugen BR, Nawaz S, Cohn A, Shroyer K, Bunn PA Jr, Liechty DR, Ridgway EC. Secondary malignancy of the thyroid gland: a case report and review of the literature. Thyroid 1994 Fall; 4: 297-300.

7. Benoit L, Favoulet P, Arnould L, et al. Metastatic renal cell carcinoma to the thyroid gland: report of seven cases and review of the literature. Ann Chir 2004; 129: 218-23.

8. Leibovich BC, Blute ML, Cheville JC, et al. Prediction of progression after radical nephrectomy for patients with clear cell renal cell carcinoma: a stratification tool for prospective clinical trials. Cancer 2003; 97: 1663-71.

9. Kaliszewski K, et al. Metastasis of renal clear cell carcinoma to the thyroid gland 20 years after nephrectomy-a case report. Nowotwory 2007; 57: 689.

10. Tang SK, Wan SK, Chan JK. Hyalinizing clear cell carcinoma of salivary gland: report of a case with multiple recurrences over 12 years. Am J Surg Pathol 1995; 19: 240-1.

11. Szlenk Z, Osuch-Wójcikiewicz E, Janczewski G. The head and neck metastases from clear cell carcinoma of the kidney. Otolaryngol Pol 1994; 48: 203-8.

12. Mierzwa T, Windorbska W, Turczyn B, Jańczak R. Wojewódzki Kujawsko-Pomorski Rejestr Nowotworów. Centrum Onkologii, Bydgoszcz 2012.

13. Cochrane TJ, Cheng L, Crean S. Renal cell carcinoma: A rare metastasis to the tongue-a case report. Dent Update 2006; 33: 186-7.

14. Rossini M, Bolzoni A, Piazza C, Peretti G. Renal cell carcinoma metastatic to the larynx. Otolaryngol Head Neck Surg 2004; 131: 1029-30.

15. Massaccesi M, Morganti AG, Serafini G, Di Lallo A, Deodato F, Picardi $\mathrm{V}$, Scambia G. Late tonsil metastases from renal cell cancer: a case report. Tumori 2009; 95: 521-4.

16. Szyfter W, Manasterski J, Turczuk-Bierła I. Difficulties in histopathologic diagnosis of the metastases of the renal clear cell carcinoma to the nasal cavity. Otolaryngol Pol 1993; 47: 295-8.

17. Hinerman RW, Parsons JT, Mendenhall WM, Stringer SP, Cassisi NJ, Million RR. External beam irradiation alone or combined with neck dissection for base of tongue carcinoma: an alternative to primary surgery. Laryngoscope 1994; 104: 1466-70.

18. Harrison LB, Zelefsky MJ, Armstrong JG, Carper E, Gaynor JJ, Sessions RB. Performance status after treatment for squamous cell cancer of the base of tongue-a comparison of primary radiation therapy versus primary surgery. Int J Radiat Oncol Biol Phys 1994; 30: $953-7$.

\section{Address for correspondence}

Piotr Sawicki, MD PhD

Department of Otholaryngology

Ludwik Rydygier Medical College in Bydgoszcz

M. Curie-Skłodowskiej 9

85-094 Bydgoszcz

e-mail: piotr.sawicki@cm.umk.pl

Submitted: 24.10 .2013

Accepted: $\quad 27.12 .2013$ 